\title{
Severe Clotting During Extracorporeal Dialysis Procedures
}

\author{
Charles J. Boyer and Richard D. Swartz
}

Division of Nephrology, Department of Internal Medicine, University of Michigan Medical Center, Ann Arbor, Michigan

The prevention of extracorporeal clotting during hemodialysis maximizes the effectiveness of treatment by maintaining patency in the dialyzer blood compartment and thereby obviating several important consequences. For example, clotting leads directly to blood loss, as much as 200-300 ml for each episode, depending on the total volume of the extracorporeal circuit. In addition, clotting reduces dialyzer clearance and thus the adequacy of dialysis treatment. Finally, clotting increases the overall cost and complications of hemodialysis.

Prevention of clotting during extracorporeal dialysis procedures is accomplished successfully in most instances using intermittent systemic heparinization and hemodialysis sometimes can be accomplished without anticoagulation at all $(1,2)$. However, occasional patients manifest extreme resistance to heparin and suffer vascular access thrombosis or recurrent severe clotting of the extracorporeal circuit. Although the latter phenomenon, severe clotting of the extracorporeal circuit, is observed infrequently $(3,4)$, it is striking and problematic when it occurs. In evaluating possible causes and appropriate treatments for such clotting, several important factors which must be considered include: the characteristics of the extracorporeal circuit and its components, intrinsic abnormalities in circulating coagulation factors, and the effects of exogenous agents on the coagulation system.

\section{Pathogenesis}

\section{Mechanical Reduction of Blood Flow}

The most common cause of increased clotting in the extracorporeal circuit during hemodialysis is reduction in blood flow, usually the result of mechanical abnormalities in the vascular access or in the extracorporeal circuit itself $(3,4)$. Most often such abnormalities are easily detected, although reduced blood flow may be more subtle in settings such as continuous arterio-venous hemofiltration in which neither blood pump nor pressure and flow monitors are employed. Therefore, mechanical reduction in blood flow should always be considered when inordinate clotting has occurred during hemodialysis or related procedures.

Address correspondence to: Richard D. Swartz, MD, Division of Nephrology. Department of internal Medicine, 3914 F Taubman Center, Box 0364, University of Michigan Medical Center, Ann Arbor, Ml 48109-0364. 71

Seminars in Dialysis-Vol 4, No 2 (Apr-June) 1991 pp 69-

\section{Interaction of Blood and Synthetic Materials}

Extracorporeal circulation of blood in synthetic tubing and devices can lead to activation of circulating inflammatory mediators such as complement components and formed elements in the blood such as WBC and platelets. This activation can occur with or without heparin and is associated with platelet aggregation, reduced platelet count and fibrin accumulation on the dialyzer membranes (5-9).

These interactions are thought to depend on the adsorption of plasma proteins on the surface of the dialyzer membrane (10), and it appears that the specific type of membrane may be important. For example, cuprophane dialyzers appear to be associated with more heparin resistance and platelet consumption when compared with polyacrylonitrile, polysulfone or polymethylmalonylacetate dialyzers $(9,11-16)$. Furthermore, even the composition of the blood tubing may be implicated, and tubing composed of silicone rubber may be associated with platelet and fibrin accumulation in excess of that observed using other plastic materials (17).

One other physical factor sometimes thought to contribute to dialyzer clotting is low dialysate $\mathrm{pH}$ (18), a consideration when using sorbent or bicarbonate dialysis systems in which dialysate $\mathrm{pH}$ may be subphysiologic at times. Finally, there is some evidence linking higher hematocrit to both improved bleeding time and platelet function as well as extracorporeal fibrin deposition (19-21). This association of hypercoagulability with increased hematocrit may counter some of the clinical benefits of erythropoietin administration in hemodialysis patients.

\section{Circulating Coagulation Cofactors}

In addition to the extracorporeal factors and interactions with synthetic materials, there are also recognized abnormalities in several intrinsic coagulation factors which might be associated with hypercoagulability and which have been described in hemodialysis patients. First among these factors is antithrombin III (AIII), a 65 kilodalton protease inhibitor synthesized in the liver. Low levels of AIII activity may occur in patients with hereditary defects in liver synthesis of AIII, with increased AIII consumption due to extensive intravascular thrombosis or to ongoing heparin administration, and with increased urinary AIII loss in nephrotic syndrome (2224). Familial AIII deficiency has been noted with a frequency of 1 in 2000-5000 of the general population, and most often involves a reduction below normal in circulating AIII activity of less than $30 \%$ 
(22). A moderate increase in heparin resistance has been associated with a $40-60 \%$ reduction in AIII activity in familial cases, while severe resistance has been noted when AIII is reduced by more than $60 \%$ $(22,23)$.

Studies in dialysis patients suggest that, in general, AIII levels may be somewhat low (25-27) and that levels may fall slightly during hemodialysis $(27,28)$; however, the extent of these changes is small and does not ordinarily result in coagulation abnormalities. Several individual cases of severe AIII deficiency associated with severe clotting have been reported among hemodialysis patients (29). Therefore, AIII deficiency should be considered when severe extracorporeal clotting occurs, particularly when mechanical causes of reduced blood flow cannot be identified and when renal failure is associated with underlying nephrotic syndrome.

Other plasma cofactors associated with hypercoagulability include protein $\mathrm{C}$, a vitamin $\mathrm{K}$ dependent plasma protein which can neutralize factors $\mathrm{V}$ and VIII, and protein S. Relatively low circulating levels of protein $\mathrm{C}$ in uremic patients, levels which may decrease further following hemodialysis, are thought to reflect platelet activation and thrombin generation during the dialysis procedure (30-32). Nonetheless, specific reports of hypercoagulability due to protein $\mathrm{C}$ or protein $\mathrm{S}$ deficiency among hemodialysis patients are anecdotal at best and require further confirmation (33). Other reports suggesting an additional role for protein $\mathrm{C}$ or protein $\mathrm{S}$ deficiency in the syndrome of skin necrosis with systemic calciphylaxis (34) leave open the possible pathogenetic effect of hypercoagulability in causing small vessel thrombosis among dialysis patients. If such pathogenetic mechanisms prove true, then abnormalities in protein $\mathrm{C}$ and protein $\mathrm{S}$ metabolism may well be implicated in many instances of hypercoagulability among hemodialysis patients.

\section{Pharmacologic Agents}

Circumstances arise in which pharmacologic agents appear to activate the coagulation system and result in increased clotting. For example, agents such as conjugated estrogens and DDAVP, which improve the bleeding time in uremic patients, have been associated with hypercoagulability and excessive clotting in hemodialysis patients $(35,36)$. In addition, erythropoietin treatment for the anemia of chronic renal failure has also been shown to improve platelet function among dialysis patients and, therefore, to be associated with possible enhancement of thrombosis $(21,37)$.

Heparin itself has even been associated with immunologic activation of platelets and resulting thrombocytopenia $(38,39)$. Furthermore, some authors feel that heparin may be responsible for the hypercoagulability associated with syndromes such as priapism in the hemodialysis setting (40). However, evidence suggests that hypercoagulability due to heparin-related platelet activation is very unusual in the general hemodialysis population (41). Finally, agents such as nitroglycerin have been reported to interfere with the anticoagulant activity of heparin and to be responsible for hypercoagulability in the non-dialysis setting (42); thus, surveillance for such phenomena in the dialysis setting is warranted.

\section{Other Clinical Settings}

Hypercoagulability has also been described in settings of striking general illness, such as septicemia, circulatory collapse, and malignancy, with or without the presence of renal failure or dialysis (43). To date no particular predisposition to hypercoagulability has been ascribed to renal failure or dialysis in these severe conditions, but it seems reasonable to expect an increased tendency toward clotting when severe illness complicates acute or chronic renal failure.

\section{Diagnosis and Treatment}

The management of extracorporeal clotting associated with hemodialysis ordinarily involves increasing the heparin dosage. However, the need to increase heparin dosage presents the clinician with a particular challenge when there is an increased risk for bleeding in a dialysis patient, since heparin will potentiate the likelihood of bleeding from any intracorporeal sites $(3,4)$. Therefore, because mechanical reduction of blood flow most often causes extracorporeal clotting and will not be amenable to increased heparin, it is appropriate to evaluate for extracorporeal occlusion or for correctable lesions such as stenosis of the vascular access before increasing heparin dosage.

Unusual cases in which specific cofactor abnormalities are identified may be amenable to replacement therapy. For example, treatment using synthetic AIII has been described in hemodialysis patients with low AIII activity (44). Alternatively, agents which inhibit platelet activation, particularly short-acting parenteral agents such as prostacyclin (45-47) or longer-acting agents such as sulfinpyrazone $(48,49)$, might be useful when hypercoagulability is associated with hyperaggregability. In some instances, the use of dialyzer membranes such as polyacrylonitrile which do not acutely activate inflammatory mediators $(9,11-16)$ may also prove useful in such hypercoagulable patients.

When heparin itself appears to contribute to the hypercoagulability, or when the pathogenesis is unclear, alternative methods for preventing extracorporeal clotting might prove useful. For example, low molecular weight heparinoids may avoid immunogenicity and prove more effective in some circumstances (50), although the specific use of these agents under circumstances of hypercoagulability in hemodialysis has not been reported. Another alternative to heparin use is regional anticoagulation using citrate plus calcium neutralization in hemodialysis (51) or in continuous arteriovenous hemofiltration (52). Finally, there are reports describing membrane materials which are bonded with heparin itself to retard clotting (53), or with heparinase (54) or prot- 
amine (55) which removes circulating heparin at the time of blood return. However, the clinical utility of these latter materials for general use is yet to be demonstrated.

\section{Conclusion}

Unfortunately, no single predominant pathogenetic entity causing hypercoagulability has been described in the dialysis setting. Therefore, no consistently successful or clearly indicated method for treating or preventing such hypercoagulability is yet available. In the meantime, rigorous clinical surveillance for abnormalities such as those outlined here may help to define at least a subset of patients for whom both pathogenesis as well as directed therapy can be identified.

\section{References}

1. Sanders PW, Taylor $\mathrm{H}$, Curtis $\mathbf{J J}$ : Hemodialysis without anticoagulation. Am J Kidney Dis 5:32-35, 1985

2. Schwab SJ, Onorato JJ, Sharar LR, Dennis PA: Hemodialysis without anticoagulation: One-year prospective trial in hospitalized patients at risk for bleeding. Am J Med 83:405-410, 1987

3. Swartz RD, Port FK: Preventing hemorrhage in high-risk hemodialysis: Regional versus low-dose heparin, Kidnev Int 16:513-518, 1979

4. Swartz R: Hemorrhage during hemodialysis using controlled heparinization. Nephron 28:65-69, 198

5. Craddock PR, Fehr J, Brigham K:, Kronenberg RS, Jacob HS: Complement and leukocyte-mediated pulmonary dysfunction in hemodialysis. $N$ Engl J Med 296:769-774, 1977

6. Hakim RM, Breillatt J, Lazarus JM, Port FK: Complement activation and hypersensitivity reactions to dialysis membranes. $N$ Engl J Med 311:878-882,1984

7. Hakim RM, Schafer AI: Hemodialysis-associated platelet activation and thrombocytopenia. Am J Med 78:575-580, 1985

8. Hildebrand $U$, Quellhorst E: Influence of various membranes on the coagulation system during dialysis. Contrib Nephrol 46:92-101, 1985

9. Moll S, de Moerloose P, Reber G, Schifffrli J, Leski M: Comparison of two hemodialysis membranes, polyacrilonitrile and cellulose acetate. on complement and coagulation systems. Int I Artif Organs 13:273279. 1990

10. Notohamiprodjo M, Andrassy $\mathbf{K}$, Bommer J, Ritz E: Dialysis membranes and coagulation system. Blood Purif 4:130-141, 1986

11. Berrettini M, Buoncristiani U, Parise P, Ballatori E, Nenci GG: Polyacrilonytrile versus cuprophan membranes for hemodialysis: Evaluation of efficacy and biocompatibility by platelet aggregation studies. Int $J$ Artif Organs 4:218-222, 1981

12. Sreharan N, Crow MJ, Salter MCP, Donaldson DR, Rajah SM, Davison AM: Membrane effect on platelet function during hemodialysis: A comparison of cuprophan and polycarbonate. Artif Organs 6:324-327, 1982

13. Docci D, Turci F, Del Vecchio C, Bilancioni R, Cenciotti L, Pretolani E: Hemodialysis-associated platelet loss: Study of the relative contribution of dialyzer membrane composition and geometry. Int J Artif Organs 7:337-340, 1984

14. Knudsen F, Nielsen AH: Polycarbonate versus cuprophan dialyzers: Effect on platelet function. Blood Purif 2:173-180, 1984

15. Vaziri N, Toohey J, Paule P, et al.: Effect of hemodialysis on contact group of coagulation factors, platelets and leukocytes. $\mathrm{Am} \mathrm{J} \mathrm{Med}$ $77: 437-441,1984$

16. Schmitt GW, Moake JL, Rudy CK, Vicks SL, Hamburger RJ: Alterations in hemostatic parameters during hemodialysis with dialyzers of different membrane composition and flow design. Am J Med 83:411418,1987

17. Bjornson J: Thrombus formation in the artificial kidney. Scand J Urol Nephrol 12:251-257, 1978

18. Schwarzbeck A. Wagner L, Squarr H-U, Strauch M: Clotting in dialyzers due to low pH of dialysis fluid. Clin Nephrol 7:125-127, 1977

19. Bjornson J, Brosstad F: Platelet and fibrin(ogen) deposition in the artificial kidney: The influence of haematocrit, fibrin monomer and platelet inhibitors. Scand J Urol Nephrol 12:259-264, 1978

20. Livio M, Benigni A, Remuzzi G: Coagulation abnormalities in uremia. Semin Nephrol 5:82-90, 1985

21. Watson AJ: Adverse effects of therapy for the correction of anemia in hemodialysis patients. Semin Nephro/ 9(Suppl 1):30-34, 1989

22. Bick RL: Clinical relevance of antithrombin III. Semin Thromb Hemost 8:276-287, 1982

23. Nielsen LE, Bell WR, Borkon AM, Neill CA: Extensive thrombus formation with heparin resistance during extracorporeal circulation.
Arch Intern Med 147:149-152, 1987

24. Marciniak E, Gockerman JP: Heparin-induced decrease in circulating antithrombin-III. Lancet 2:581-584, 1977

25. Jorgensen KA, Stoffersen E: Antithrombin 111 in uremia. Scand J Urol Nephrol 13:299-303, 1979

26. Knudsen F, Dyerberg J: Platelets and antithrombin III in uremia: The acute effect of hemodialysis. Scand J Clin Lab Invest 45:341-347, 1985

27. Toulon $\mathrm{P}$, Jacquot $\mathrm{C}$, Capron L, Frydman M-O, Vignon D, Aiach $M$ Antithrombin III and heparin cofactor II in patients with chronic renal failure undergoing regular hemodialysis. Thromb Haemost 57:263268, 1987

28. Brandt P, Jespersen J, Sorensen LH: Antithrombin-III and platelets in haemodialysis patients. Nephron 28:103, 1981

29. Matsuo T, Yamada T, Yamanashi T, Kodama K: Choice of anticoagulant in 9 congenital antithrombin III deficient patients with chronic renal failure undergoing regular hemodialysis. Clin Lab Haematol $11: 213-219,1989$

30. Alegre A, Vicente V, Gonzalez R, Alberca I: Effect of hemodialysis on protein C levels. Nephron $46: 386-387,1987$

31. Sorensen $P$, Nielsen $A$, Knudsen F, Dyerberg $\mathbf{J}$ : Defective protein $C$ in uremia. Blood Purif 5:29, 1987

32. Knudsen F, Sorensen PJ, Nielsen AH, Dyerberg J: Functional impairment of protein $\dot{C}$ activity during haemodialysis-a new mechanism of extracorporeal thrombogenesis. Blood Purif 7:230-232, 1989

33. Henke WJ: Protein $\mathrm{C}$ and $\mathrm{S}$ response to danacrine in end-stage renal disease. Ann Int Med 106:910, 1988

34. Mehta R, Scott G, Sloand J, Francis C: Skin necrosis associated with acquired protein $\mathrm{C}$ deficiency in patients with chronic renal failure. Am I Med 88:252, 1990

35. Livio M, Mannucci $P$, Vigano $G$, et al.: Conjugated estrogens for the management of bleeding associated with renal failure. $N$ Engl J Med $315: 731,1986$

36. Byrnes JJ, Larcada A, Moake JL: Thrombosis following desmopressin for uremic bleeding. Am J Hematol 28:63-65, 1988

37. El-Shahaway MA. Francis R, Akmel M, Massry SG: Recombinan human erythropoietin shortens bleeding time and corrects abnormal platelet aggregation in hemodialysis patients (Abstract). $J$ Amer Soc Nephrol 1:397, 1990

38. Babcock RB, Dumper CW, Scharfman WB: Heparin-induced immune thrombocytopenia. $N$ Engl J Med 295:237-241, 1976

39. King DJ, Kelton JG: Heparin-associated thrombocytopenia. Ann Int Med 100:535-540, 1984

40. Selli C, Amato M, Salvadori M: Priapism associated with chronic hemodialysis. Dial Transpl 15:101, 1986

41. Pusineri F, Bini A, Mussoni L, et al.: Intermittent heparinization does not induce hypercoagulability in haemodialysis patients. $J$ Clin Patho $33: 631,1980$

42. Habbib $M$, Haft $J$ : Heparin resistance induced by intravenous nitroglycerin: A word of caution when both drugs are used concomitantly. Arch Int Med 147:857, 1987

43. Penner JA: Hypercoagulation and thrombosis. Med Clin North Am $64: 743-759,1980$

44. Kelly A, Hanson J, Henderson L, Harker L: Prevention of heparinresistant thrombotic occlusion of hollow fiber hemodialyzers by synthetic antithrombin III. $J$ Lab Clin Med 114:411, 1989

45. Zusman RM, Rubin RH, Cato AE, Cocchetto DM, Crow JW, TolkoffRubin N: Hemodialysis using prostacyclin instead of heparin as the sole antithrombotic agent. $N$ Engl J Med 304:934-939, 1981

46. Smith MC, Danviriyasup K, Crow JW, Cato AE, Park GD, Hassid A Dunn MJ: Prostacyclin substitution for heparin in long-term hemodialysis. Am J Med 73:669-678, 1982

47. Swartz R, Flamenbaum W, Dubrow A, et al.: Epoprostenol (PGI2 prostacyclin) during high-risk hemodialysis: Preventing further bleeding complications. J Clin Pharmacol 28:818, 1988

48. Woods H, Ash G, Parsons V, Weston M: Reduction of dialyzer deposition with sulphinpyrazone. Clin Nephrol 12:122, 1979

49. Maurin N, Ballmann M: Prevention of coagulation during hemodialysis by a combination of the stable prostacyclin analogue CG 4203 and low-dose heparin. Clin Nephrol 30:35, 1988

50. Henny $C$, Ten Cate $H$, Surachno $S$, et al:: The effectiveness of a low molecular weight heparinoid in chronic intermittent haemodialysis. Thromb Haemost 54:460, 1985

51. Pinnick R, Weigmann $T$, Diderich D: Regional citrate anticoagulation for hemodialysis in the patient at high risk for bleeding. $N$ Engl $J \mathrm{Med}$ 308:258, 1983

52. Mehta RL, McDonald BR. Aguilar MM, Ward DM: Regional citrate anticoagulation for continuous arteriovenous hemodialysis in critically ill patients. Kidney Int 38:976-981, 1990

53. Toomasian JM, Helmer GA, Zeme MI, Oltean JN, Oran AD, Bartlett $\mathrm{RH}$ : Control of thrombosis in extracorporeal circulation: Variations of anticoagulation. Trans Am Soc Artif Organs 29:206-209, 1983

54. Langer R. Linhardt RJ, Hoffberg S. Larsen AK, Cooney CL, Tapper D, Klein M: An enzymatic system for removing heparin in extracorporeal therapy. Science 217:261-263, 1982

55. Teng C-LC, Kim J-S, Port FK, Wakefield TW, Till GO, Yang VC: A protamine filter for extracorporeal blood heparin removal. Trans Am Soc Artif Organs 34:743-746, 1988 